\title{
Vulnerability of Pinus densiflora to forest fire based on ignition characteristics
}

\author{
Hyungsoo Seo ${ }^{1}$ and Yeonsook Choung ${ }^{2, *}$ \\ ${ }^{1}$ Ecology Research Department, National Institute of Environmental Research, Incheon 404-708, Korea \\ ${ }^{2}$ Department of Biological Sciences, Kangwon National University, Chuncheon 200-701, Korea
}

In Korea, man-caused forest fires are known originate primarily in coniferous forests. We have hypothesized that the vulnerability of Pinus densiflora forests is principally a consequence of the ignition characteristics of the species. To assess this hypothesis, we conducted two combustion experiments using fallen leaves with a reference species, Quercus variabilis. In the first experiments, in which a cigarette was employed as a primary heat source for the initiation of a forest fire, the Pinus leaves caught fire significantly faster (1'1" at Pinus, 1'31" at Quercus, P<0.001), and ignition proceeded normally. Quercus leaves, on the other hand, caught fire but did not ignite successfully. In the second set of experiments utilizing different moisture contents and fuel loads, the maximum flame temperature of the Pinus leaves was significantly higher $\left(421^{\circ} \mathrm{C}\right.$ at Pinus, $361^{\circ} \mathrm{C}$ at Quercus, $\left.P<0.001\right)$ and the combustion persisted for longer than in the Quercus leaves (8'8" at Pinus, 3'38" at Quercus, $P<0.001$ ). The moisture contents of the leaves appeared to be a more important factor in the maximum temperature achieved, whereas the most important factor in burning time was the amount of fuel. Overall, these results support the assumption that Pinus leaves can be ignited even by low-heat sources such as cigarettes. Additionally, once ignited, Pinus leaves burn at a relatively high flame temperature and burn for a prolonged period, thus raising the possibility of frequent fire occurrences and spread into crown fires in forests of $P$. densiflora.

Key words: burning time, cigarette, forest fire, ignition characteristics, maximum flame temperature, Pinus densiflora, Quercus variabilis, vulnerability

\section{INTRODUCTION}

Fires require three factors: fuel, oxygen, and heat (Chandler et al. 1983). Litter, branches, and woody debris are the main fuels implicated in forest fires. In particular, fine fuels such as dried fallen leaves and small branches are regarded as an important factor in the ignition stage (Chandler et al. 1983, Haessler 1989). Once ignited, forest fires move into the spread stage, evidencing a variety of behaviors and intensities depending on the amount of fuel, as well as meteorological or geographical factors (Burgan and Rothermel 1984).

Lee et al. (2005) analyzed forest fire records across the country, and concluded that the initial ignition of forest fires most frequently occurs in coniferous forests $(69 \%)$, followed by mixed forests $(17 \%)$ and broadleaf forests $(14 \%)$, respectively. In this regard, three possibilities have been raised as to why forest fires occur primarily in coniferous forests. First, coniferous forests are characterized by a wide spread, and thus they are very likely to be exposed to people, resulting in a higher possibility of mancaused fires. Second, coniferous trees exist principally at lower elevations near villages or memorial parks, which are easily accessed by humans. Finally, the ignition char- (c) This is an Open Access article distributed under the terms of the Creative Commons Attribution Non-Commercial License (http://creativecommons.org/licenses/by-nc/3.0/) which permits unrestricted non-commercial use, distribution, and reproduction in any medium, provided the original work is properly cited.
Received 16 July 2010, Accepted 09 August 2010

${ }^{*}$ Corresponding Author

E-mail: yschoung@kangwon.ac.kr

Tel: +82-33-250-8529 
acteristics of coniferous trees in Korea are responsible to their vulnerability of fire.

It has been reported previously that $42 \%$ of domestic forests are coniferous forests, while $26 \%$ are broadleaf forests. In the East Coast regions (Goseong, Yangyang, Sokcho, Gangneung, Donghae, and Samcheok) of Gangwon province, where large forest fires most frequently occur, the forest composition is as follows: $38 \%$ coniferous, $29 \%$ broadleaf and other forests (Korea Forest Service 2009). Coniferous forests cover a wider area than broadleaf forests. However, the ratio of forest fires in coniferous forests is $69 \%$, which is far higher than their proportions relative to other forest types; this cannot be sufficiently explained for the first reason listed above, although it is true that more coniferous forests are distributed throughout regions of lower elevation. The pre-fire vegetation of the East Coast fires region in 2000 was characterized by a relatively high frequency of Pinus densiflora forests, the most dominant forest type among coniferous forests, at lower elevations (Choung et al. 2004). This may, to some degree, be related to that region's general susceptibility to fire. Clearly, coniferous trees are more likely to encounter heat sources; however, if the fuel cannot be ignited, no fire can start. Thus, greater access to forests by humans is not, in and of itself, a satisfying explanation for the increased vulnerability of coniferous forests to fire.

Therefore, the frequent occurrences of fire in coniferous forests are assumedly attributable to the ignition characteristics of coniferous trees at the ignition stage. $P$. densiflora harbors a variety of volatile substances, such as resins and terpene, in its timber, cambium, leaves, and branches (Song and Kim 1994). Additionally, its organs contain a large caloric content (Park et al. 2007) which potentially increase firing possibility and allow for prolonged combustion.

In Korea, most fires have been identified as mancaused fires. Forty nine percent of fires are reported by people visiting the graves of family members in mountains or memorial parks which are commonly located in lowland mountainous regions. Thus far, $10 \%$ of fires were identified as being directly induced by cigarettes. However, the actual percentile is assumed to be substantially higher than reported. Kim et al. (1994) demonstrated that the coniferous species, . rigida and Larix leptolepis, catch fire more quickly than the broadleaf species, Quercus acutissima, when employing cigarettes as a heat source. However, the responses of $P$. densiflora and Q. variabilis to cigarettes have yet to be evaluated, even though these are the predominant tree species in the relevant areas.

The principal objective of this study was to prove that the ignition characteristics of $P$. densiflora forests are one of the major factors in their susceptibility to fire. We compared the ignition characteristics of P. densiflora with $Q$. variabilis, which was utilized as a reference species. Q. variabilis either coexists, or forms pure stands in the neighbourhood of P. densiflora stands in Korea. This study involved two related experiments. The first of these experiments was conducted to compare the possibility of the firing and ignition of Pinus and Quercus leaves with different moisture contents, using a cigarette as a heat source. The second experiment involved the measurement of maximum burning temperatures and burning time of Pinus and Quercus leaves of differing moisture contents and fuel loads. Firing is defined as the process by which a substance catches fire after exposure to an ignition source. In firing, smoke, but no flame, is produced. If the ignition source is removed, the substance will not continue to burn. Ignition, however, is defined as the production of flames subsequent to firing. A successfully ignited substance continues to burn even when the ignition source is removed.

\section{MATERIALS AND METHODS}

\section{Collecting fuel source}

Fallen leaves were employed as a fine fuel source, as it evidences higher combustibility and can be readily ignited. In our experiment, fallen leaves of $P$. densiflora and Q. variabilis were collected from the forests of Seongsanmyeon and Sacheon-myeon, Gangneung-si, Gangwondo, respectively, in the summer and autumn of 2008. Both P. densiflora and Q. variabilis forests largely exist as pure stands consisting of trees in their thirties. The collected leaves were dried in a drying oven at $60^{\circ} \mathrm{C}$ until their weight no longer changed.

\section{Combustion experiment}

Assuming that a cigarette is a primary heat source in forest fires, we conducted firing and ignition experiments with fallen leaves with differing moisture contents. The moisture contents were adjusted by spraying water evenly onto $20 \mathrm{~g}$ of dried leaves at $0 \%, 5 \%$, and $10 \%(\mathrm{v} / \mathrm{w})$ in plastic bags. The plastic bags were kept tight and were shaken until the combustion experiments began the next day. The moisture contents ratios were established on the basis of the moisture contents of fine fuels in $P$. densiflora and Q. variabilis forests through the fall and 

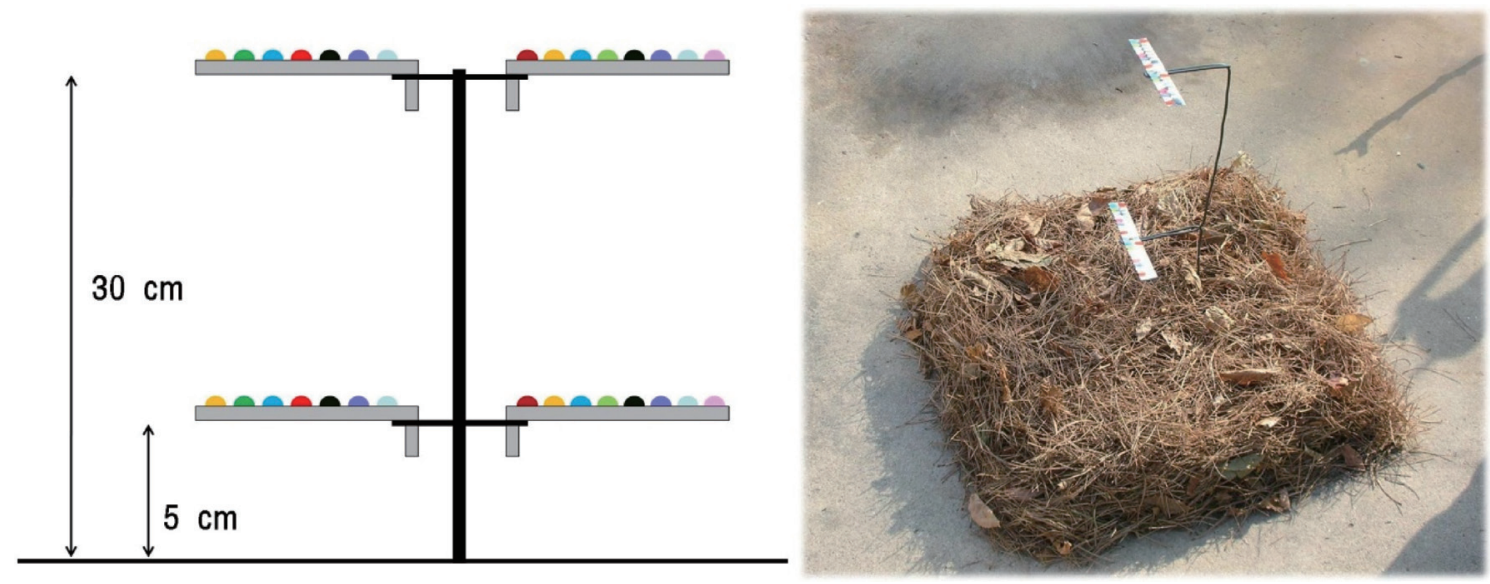

Fig. 1. Thermocolor pyrometer modified from Graham and McCarthy (2006).

spring seasons in the field, as demonstrated previously by Seo (2010). Firing and burning time were measured by the insertion of a cigarette $1 \mathrm{~cm}$ into a $10 \mathrm{~cm} \times 10 \mathrm{~cm}$ cluster of leaves. We repeated the same test five times for each of the moisture contents. These experiments were conducted in an open area on June 14, 2009. Wind speed was in the range of 0-1.2 m/s, and the air temperature and relative humidity were $21.5-23.9^{\circ} \mathrm{C}$ and $54.6-63.1 \%$, respectively.

In the second experiment, we burned leaves with differing moisture contents and quantities of fuel, and then determined the maximum burning temperature and burning time. The moisture contents were adjusted to $0 \%, 5 \%$, and $10 \%$ in the same fashion as was established for the above test. Both $300 \mathrm{~g}$ and $600 \mathrm{~g}$ of the $50 \mathrm{~cm} \times 50$ $\mathrm{cm}$ cluster of leaves $\left(1,200 \mathrm{~g}\right.$ and $2,400 \mathrm{~g}$ per $\mathrm{m}^{2}$, respectively) were set on the basis of the amount of leaves in a natural setting, according to Seo (2010), on the ground. A torch was then used to set fire to the leaves. To measure the temperature of the flame, we designed a thermocolor pyrometer modified from the research of Graham and McCarthy (2006). The thermocolor pyrometer consists of 15 different $\mathrm{Tempilaq}^{\circ} \mathrm{G}$ liquid paints on aluminum tags with various melting points $(79,107,135,163,191,218$, $246,274,316,371,427,482,538,593$, and $\left.649^{\circ} \mathrm{C}\right)$. Two of the thermocolor pyrometers were set at heights of $5 \mathrm{~cm}$ and $30 \mathrm{~cm}$ on the right and left (Fig. 1). The maximum burning temperature was determined by checking the melted paint on the right and left aluminum tags. We measured the burning time when the leaves had burnt completely. The second experiments were repeated four times in the open area at two different days, April 18 and May 30, 2009. On April 18, the wind speed was in a range of $1.9-2.8 \mathrm{~m} / \mathrm{s}$, and the air temperature and relative hu- midity were $21.7-25.5^{\circ} \mathrm{C}$ and $13.4-21.1 \%$, respectively. On May 30, the wind speed was in a range of $0-1.2 \mathrm{~m} / \mathrm{s}$, and the air temperature and relative humidity were 16.4$22.4^{\circ} \mathrm{C}$ and $33.4-54.4 \%$, respectively. The results from the two different days were averaged.

\section{Statistical analysis}

We used an analysis of variance to assess significant differences between species, moisture contents and fuel loads on firing time, maximum temperature, and burning time. Mean differences were analyzed via Bonferroni's post hoc test. Multiple regression analysis was employed to determine the relative effects of burning temperature and time. SYSTAT ver. 10 (SPSS Inc., Chicago, IL, USA) software was employed to process the results of the analyses.

\section{RESULTS AND DISCUSSION}

\section{Firing and ignition by cigarette}

Pinus leaves were set on fire with a cigarette, after which ignition proceeded normally, whereas Quercus leaves caught fire but did not proceed to full ignition (Fig. 2). Pinus (average $1^{\prime} 1^{\prime \prime}$ ) appeared to catch fire more quickly than Quercus (average 1'31"). The difference between the two species was statistically significant $(F=28.9, P<$ 0.001 ) (Table 1). With increases in the moisture contents, more firing time was required. Pinus leaves caught fire 1.8 times and 1.2 times more quickly than Quercus leaves when the moisture contents were $0 \%$ and $10 \%$, respectively. Moisture content appeared to affect the firing time 
significantly $(F=4.1, P<0.05)$ (Table 1$)$. This was clearer in the Pinus leaves, but no significant trend was noted in the Quercus leaves (Fig. 2). Based on the moisture contents, the firing time of the Pinus leaves was measured at an average $5^{\prime} 42^{\prime \prime}$ for $0 \%, 7^{\prime} 32^{\prime \prime}$ for $5 \%$, and $9^{\prime} 10^{\prime \prime}$ for $10 \%$.

Seo (2010) monitored the varying moisture contents of fine fuel from P. densiflora and Q. variabilis forest stands in Gangneung-si, Gangwon-do over the year. The moisture content appeared to decline significantly after summer, and was lowest in the spring. In April, the average moisture content of the fine fuel was $7.2 \%$ in P. densiflora stands and $6.7 \%$ in $Q$. variabilis stands. The moisture contents between $P$. densiflora and $Q$. variabilis stands did not differ significantly. By adopting the moisture content of April to the results of this study, it can be assumed that it would require approximately $8^{\prime} 15^{\prime \prime}$ for a $P$. densiflora forest stand to be ignited by cigarettes. April is the most active fire season in Korea.

Such results support the hypothesis that cigarette butts thrown in the forest during the spring season can cause fine fuels to catch fire, and may possibly ignite forest fires in $P$. densiflora forests. The reason that $P$. densiflora can so readily catch fire may involve the volatility of its resins or terpenes (Song and Kim 1994). Additionally, coniferous trees evidence a higher surface area/volume ratio due to their shape (Hely et al. 2000) such that coniferous trees like P. densiflora are exposed to larger surfaceto-ignition sources than other broadleaf trees such as $Q$. variabilis for the same volume. Kim et al. (1994) also noted that coniferous forests (pitch pine, larch, etc.) caught fire for shorter periods of time than broadleaf trees (eg. Q. acutissima) when exposed to a burning cigarette. Furthermore, Lee et al. (2009) reported previously that fallen leaves containing lower moisture contents caught fire for shorter periods of time than live leaves, because their natural burning temperature is lower.

\section{Maximum burning temperature and burning time}

We burned the leaves of Pinus and Quercus with various amounts of fuel and moisture contents in order to determine the maximum burning temperature and burning time of these materials. Pinus leaves at a height of $5 \mathrm{~cm}$ evidenced an average burning temperature of $421^{\circ} \mathrm{C}$, which is approximately 1.8 times the average burning temperature of $329^{\circ} \mathrm{C}$ at a height of $30 \mathrm{~cm}$ (Fig. 3). The burning temperature of Quercus leaves at a height of $5 \mathrm{~cm}$ was $361^{\circ} \mathrm{C}$ on average, which is approximately 1.5 times the average burning temperature of $239^{\circ} \mathrm{C}$ measured at a height of $30 \mathrm{~cm}$.

Both species appeared to have the highest burning temperature with the lowest moisture contents, and the burning temperature increased as the quantity of fuel increased as well. Pinus leaves at a height of $5 \mathrm{~cm}$ had the highest average burning temperature of $473^{\circ} \mathrm{C}$ at a moisture content of $0 \%$, and an average of $441^{\circ} \mathrm{C}$ at $5 \%$

Table 1. Analysis of variance for the effects of firing time (two-way), maximum temperature, and burning time (three-way)

\begin{tabular}{|c|c|c|c|c|c|c|}
\hline & Source & d.f & $N$ & Mean square & $F$-ratio & $P$-value \\
\hline \multirow[t]{3}{*}{ Firing time } & Species & 1 & 24 & $5,551.042$ & 28.889 & 0.001 \\
\hline & Moisture & 2 & 24 & 790.292 & 4.113 & 0.034 \\
\hline & Error & 18 & 24 & 192.153 & & \\
\hline \multirow[t]{4}{*}{ Maximum temperature at $5 \mathrm{~cm}$} & Species & 1 & 45 & $65,935.951$ & 13.965 & 0.001 \\
\hline & Moisture & 2 & 45 & $21,307.734$ & 4.513 & 0.019 \\
\hline & Fuel load & 1 & 45 & $23,765.438$ & 5.033 & 0.032 \\
\hline & Error & 33 & 45 & $4,721.593$ & & \\
\hline \multirow[t]{4}{*}{ Maximum temperature at $30 \mathrm{~cm}$} & Species & 1 & 46 & 235.930 & 0.037 & 0.850 \\
\hline & Moisture & 2 & 46 & $38,410.704$ & 5.951 & 0.006 \\
\hline & Fuel load & 1 & 46 & $14,103.719$ & 2.185 & 0.149 \\
\hline & Error & 34 & 46 & $6,454.167$ & & \\
\hline \multirow[t]{4}{*}{ Burning time } & Species & 1 & 44 & $646,287.019$ & 104.424 & 0.000 \\
\hline & Moisture & 2 & 44 & $28,599.508$ & 4.621 & 0.017 \\
\hline & Fuel load & 1 & 44 & $133,700.252$ & 21.603 & 0.000 \\
\hline & Error & 32 & 44 & $6,189.076$ & & \\
\hline
\end{tabular}

Interaction terms, which are not significant, are not shown. 

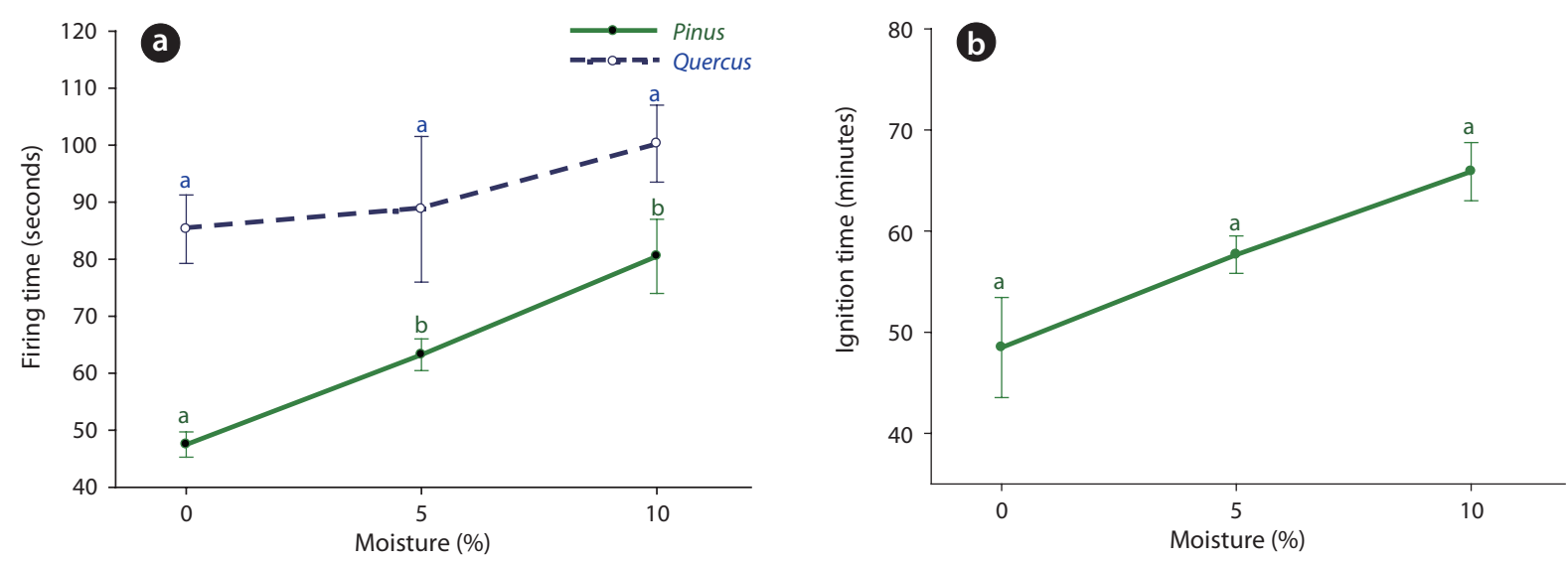

Fig. 2. Firing (a) and ignition time (b) of Pinus and Quercus leaves by cigarette. Average \pm 1 standard error is given $(N=5)$. Different letters by Bonferroni post-hoc test indicate the significant mean difference between moisture conditions within species.
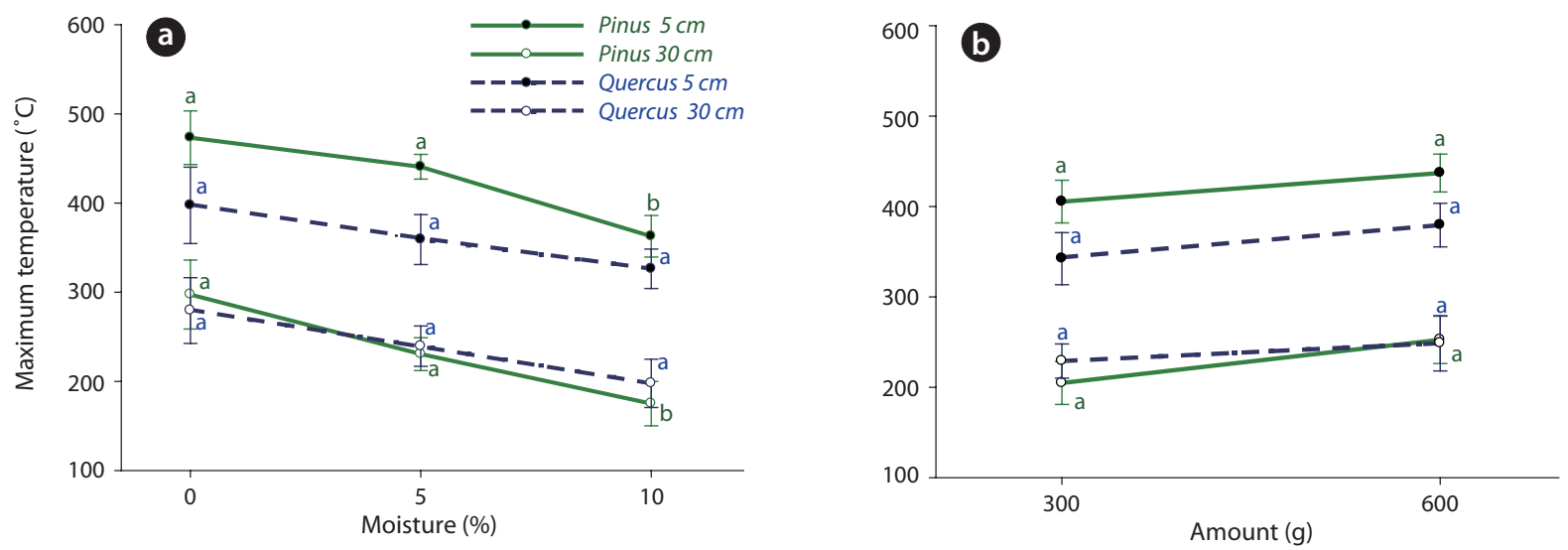

Fig. 3. Maximum burning temperature of Pinus and Quercus leaves measured at two heights $(5 \mathrm{~cm}$ and $30 \mathrm{~cm})$ according to different fuel moisture contents (a) and fuel loads (b). Average \pm 1 standard error is given $(N=4)$. Different letters by Bonferroni post-hoc test indicate the significant mean difference between treatments within species.
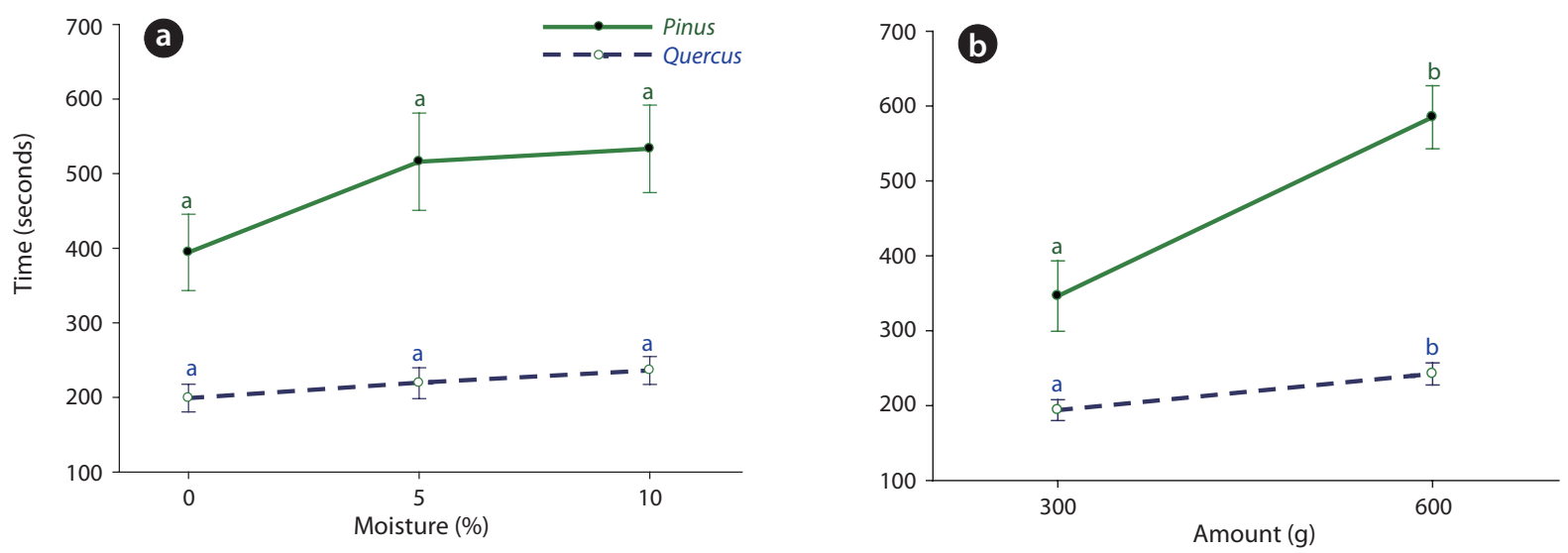

Fig. 4. Burning time according to different fuel moisture contents (a) and fuel loads (b). Average \pm 1 standard error is given $(N=4)$. Different letters by Bonferroni post-hoc test indicate the significant mean difference between treatments within species. 
and an average of $363^{\circ} \mathrm{C}$ at $10 \%$ (apparently the lowest temperature in the tested ranges). When the quantity of Pinus leaves was $600 \mathrm{~g}$ at a height of $5 \mathrm{~cm}$, the burning temperature was an average of $437^{\circ} \mathrm{C}$, which is approximately 1.1 times the average of $405^{\circ} \mathrm{C}$ measured with a mass of $300 \mathrm{~g}$.

According to the analysis of variance with the maximum burning temperatures between two species for various moisture contents and fuel amounts (Table 1), we noted that the maximum temperature of Pinus at a height of $5 \mathrm{~cm}$ was significantly higher than that of Quercus $(F=14.0, P<0.001)$. However, no significant differences were noted between the two species at a height of $30 \mathrm{~cm}$. The maximum temperature at various moisture contents differed significantly at heights of $5 \mathrm{~cm}$ and 30 $\mathrm{cm}$, whereas the maximum temperature for different fuel loads was significant only at a height of $5 \mathrm{~cm}$ (Table 1). At a height of $30 \mathrm{~cm}$, flames occasionally failed to reach the thermocolor pyrometer due to the effects of wind, which likely resulted in substantial deviation. The results of multiple regression analysis showed that moisture contents are more important than the quantity of fuel for the maximum temperature at heights of $5 \mathrm{~cm}(F=8.253, P<$ $0.01)$ and also $30 \mathrm{~cm}(F=8.064, P<0.001)$.

The burning time of Pinus leaves appeared to be influenced by moisture contents or by the quantity of fuel (Table 1). On the other hand, Quercus leaves did not appear to be affected. At a moisture content of $0 \%$, the burning time of Pinus was an average of 6 '35", and was measured at an average of $8^{\prime} 23^{\prime \prime}$ and $8^{\prime} 53^{\prime \prime}$ at $5 \%$ and $10 \%$, respectively (Fig. 4). The average burning time of Pinus was 8'8" whereas the average of Quercus was 3'38". Accordingly, Pinus burned approximately 2.2 times longer than Quercus. Such differences are statistically significant $(F=$ 104.4, $P<0.001$ ) (Table 1).

In particular, with increases in the quantity of fuel, Pinus leaves required longer burning time. That is, 600 g of Pinus leaves required 9'38" to burn, which is approximately 1.5 times longer than the $6{ }^{\prime} 16^{\prime \prime}$ average determined with $300 \mathrm{~g}$ of leaves. To enhance the burning process, more space between leaves is required, as this allows for oxygen to be provided to the flames. However, Pinus leaves are dense and needle-shaped, which may keep oxygen outside the leaf mass. This may cause Pinus to burn more slowly. Furthermore, Pinus leaves have a higher caloric content, at 5,231 cal/g, than Quercus leaves, at 4,850 cal/g (Park et al. 2007). This appears to be attributable to the resin components of $P$. densiflora trees (Song and Kim 1994, Aerts 1997). According to the results of multiple regression for the effects of various moisture contents and fuel quantities on burning time, it appears that the amount of fuel is a more important factor than the moisture contents at a height of $5 \mathrm{~cm}(F=4.729, P<$ $0.014)$. In the spring season, $Q$. variabilis forests contain approximately 1.3 times as much fine fuel as P. densiflora forests (Seo 2010).

Nevertheless, the fact that forest fires occur less frequently in broadleaf forests such as Quercus forests is believed to be attributable to the difficulty of initial ignition of Quercus leaves by a cigarette, as was demonstrated in our test with the leaves of $Q$. variabilis. With the combination of weather conditions and forest composition in addition to the ignition characteristics of $P$. densiflora, forest fires would be expected to occur more frequently and inflict more severe damage in coniferous forests such as P. densiflora forests, than in broadleaf forests.

As a short-term plan, we recommend that specific areas densely forested with $P$. densiflora at lower altitude should be identified as vulnerable fire zones. Public access to these zones should be controlled, particularly in the severely dry spring months. Eventually, Pinus-dominated forests will be replaced by mixed forests or broadleaf forests by succession, resulting in greater resistance to heat sources.

\section{ACKNOWLEDGMENTS}

This study was supported by the Long-Term Ecological Research Programme of the Ministry of Environment, Republic of Korea. We would like to thank Dong-Jin Park and Ji-Sun Lee for their support.

\section{LITERATURE CITED}

Aerts R. 1997. Climate, leaf litter chemistry and leaf litter decomposition in terrestrial ecosystems: a triangular relationship. Oikos 79: 439-449.

Burgan RE, Rothermel RC. 1984. BEHAVE: Fire Behavior Prediction and Fuel Modeling System-Fuel Subsystem. General Technical Report INT-167. U.S. Department of Agriculture, Forest Service, Intermountain Forest and Range Experiment Station, Ogden, UT.

Chandler C, Cheney P, Thomas P, Trabaud L, Williams D. 1983. Fire in Forestry: Vol. 1. Forest Fire Behavior and Effects. John Wiley \& Sons, New York, NY.

Choung Y, Lee BC, Cho JH, Lee KS, Jang IS, Kim SH, Hong SK, Jung HC, Choung HL. 2004. Forest responses to the large-scale east coast fires in Korea. Ecol Res 19: 43-54. 
Graham JB, McCarthy BC. 2006. Effects of fine fuel moisture and loading on small scale fire behavior in mixed-oak forests of southeastern Ohio. Fire Ecol 2: 100-114.

Haessler WM. 1989. Fire: Fundamentals and Control. Marcel Dekker, Inc., New York, NY.

Hely C, Bergeron Y, Flannigan MD. 2000. Effects of stand composition on fire hazard in mixed-wood Canadian boreal forest. J Veg Sci 11: 813-824.

Kim KS, Jang IS, Kim SJ. 1994. Moisture content of litter layer and its combustibility by cigarette light in forest. Korean J Ecol 17: 1-9. (in Korean)

Korea Forest Service. 2009. National forest statistics. http:// www.forest.go.kr/foahome/user.tdf?a=user.localstat. LocalStatApp \&c=1001\&mc=WWW_INFORMATION_ST AT_010\&aYear $=2008 \&$ agubun $1=1 \&$ asido $=2 \&$ argub un=1. Accessed 26 November 2009.

Lee HP, Lee SY, Park YJ. 2009. A study on thermal characteristics and ignitability of dead leaves and living leaves for main species of trees in Youngdong areas. J Korean Inst Fire Sci Eng 23: 21-32. (in Korean)

Lee SY, Won MS, Han SY. 2005. Developing of forest fire occurrence danger index using fuel and topographical characteristics on the condition of ignition point in Korea. Trans Korean Inst Fire Sci Eng 19: 75-79. (in Korean)

Park HJ, Kim, ES, Kim JH, Kim DH. 2007. A combustion characteristic analysis of Quercus variabilis and Pinus densiflora fallen leaves using radiation heat flux. J Korean Inst Fire Sci Eng 21: 41-46. (in Korean)

Seo H. 2010. Comparison of fire vulnerability at Pinus densiflora and Quercus variabilis forests in East Coast of Korea. MS Thesis. Kangwon National University, Chuncheon, Korea.

Song HK, Kim JK. 1994. Essential oil components of leaves and resins from Pinus densiflora and Pinus koraiensis. Mokchae Konghak 22: 59-67. (in Korean) 